\title{
Synthesis of heterosulfamates. Search for structure-taste relationships
}

\author{
Wm. J. Spillane, ${ }^{a *}$ Lorraine M. Kelly, ${ }^{a}$ Brendan G. Feeney, ${ }^{a}$ Michael G. B. Drew, ${ }^{b}$ and \\ Channa K. Hattotuwagamab
}

${ }^{a}$ Chemistry Department, National University of Ireland, Galway, Ireland

${ }^{b}$ Chemistry Department, University of Reading, Reading, U.K.

E-mail: William.Spillane@nuigalway.ie

\section{Dedicated to Professor M. Anthony McKervey on his 65th birthday}

(received 11 Mar 03; accepted 26 Jun 03; published on the web 01 Jul 03)

\begin{abstract}
Thirty one new sodium heterosulfamates, $\mathrm{RNHSO}_{3} \mathrm{Na}$, where the $\mathrm{R}$ portion contains mainly thiazole, benzothiazole, thiadiazole and pyridine ring structures, have been synthesized and their taste portfolios have been assessed. A database of 132 heterosulfamates (both open-chain and cyclic) has been formed by combining these new compounds with an existing set of 101 heterosulfamates which were previously synthesized and for which taste data are available.

Simple descriptors have been obtained using (i) measurements with Corey-Pauling-Koltun (CPK) space-filling models giving $\mathrm{x}, \mathrm{y}$ and $\mathrm{z}$ dimensions and a volume $\mathrm{V}_{\mathrm{CPK}}$, (ii) calculated first order molecular connectivities $\left({ }^{1} \chi^{\mathrm{v}}\right)$ and (iii) the calculated Spartan program parameters to obtain HOMO, LUMO energies, the solvation energy $E_{\text {solv }}$ and $V_{\text {SPARTAN. The techniques of linear }}$ (LDA) and quadratic (QDA) discriminant analysis and Tree analysis have then been employed to develop structure-taste relationships (SARs) that classify the sweet (S) and non-sweet (N) compounds into separate categories.

In the LDA analysis $70 \%$ of the compounds were correctly classified (this compares with 65 $\%$ when the smaller data set of 101 compounds was used) and in the QDA analysis $68 \%$ were correctly classified (compared to $80 \%$ previously). TheTree analysis correctly classified $81 \%$ (compared to $86 \%$ previously). An alternative Tree analysis derived using the Cerius2 program and a set of physicochemical descriptors correctly classified only $54 \%$ of the compounds.
\end{abstract}

Keywords: Heterosulfamates, taste, sweetness, bitterness, SARs, cyclamates 


\section{Introduction}

Since the chance discovery in 1946 of the sweetness of some sodium thiazolesulfamates (Figure 1) by Hurd and Kharasch ${ }^{1}$ many groups Worldwide have been making and tasting heterosulfamates both open-chain and cyclic. Hurd and Kharasch ${ }^{1}$ had been studying the rearrangement of the sulfonate group (from the nitrogen to the ring) of these compounds and probably only tasted them because of the (then) recent seminal work of Audrieth and Sveda ${ }^{2}$, who had reported the sweetness of a number of non-heterosulfamates.

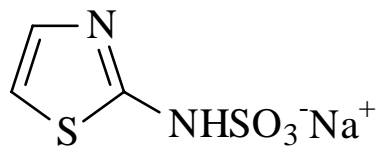

Sweet (S)

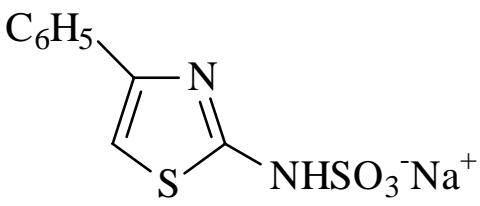

Non-sweet $(\mathrm{N})$

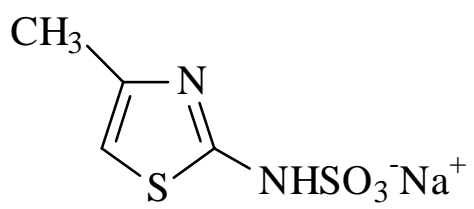

Sweet (S)

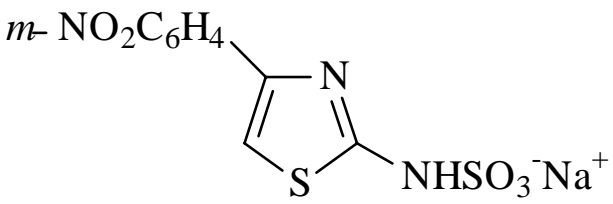

Non-sweet $(\mathrm{N})$

Figure 1. Some sweet (S) and non-sweet (N) thiazoles.

The heterosulfamates synthesized for tastant studies prior to this present work represent a large number of structural types e.g. pyridines, pyrrolidines, piperidines, pyrimidines, oxazoles, morpholines, thiazoles, benzothiazoles, thiophenes, thiacyclohexyls, thiadiazoles, etc. Table 1 contains a chronological listing of all the groups involved giving also the year(s), location and the number of compounds synthesized in each case.

In all 101 compounds were made and had taste assessments carried out. The structures of these can be found in our previous papers and thus compounds no. $\mathbf{1}-33$ are in ref. 10, compounds no. $\mathbf{3 4 - 5 6}$ in ref. 11 and compounds $\mathbf{5 7 - 1 0 1}$ in ref. 12. The structures of the thirty one newly synthesized compounds presented in this current work i.e. compounds no. $102-132$ will be found in Figure 2. They are principally thiazoles, benzothiazoles, thiadiazoles and pyridines. The first three categories were known to contain quite a few sweet compounds (based on data from the 101 compounds) and hence the synthetic effort here in this work has focused mainly on these classes. Each of these groups contain a sulfur atom and sulfur has been well recognized as a sweet taste potentiator. ${ }^{17}$ 
<smiles>Cc1nc2c(C)cccc2s1</smiles>

102<smiles>Cc1ccc2nc(S)sc2c1</smiles>

107<smiles>CCCc1ccc(C)nc1C</smiles>

112<smiles>CCc1nnc(C)s1</smiles>

117

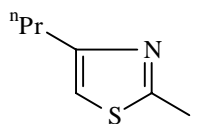

122

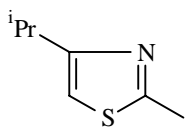

127<smiles>Cc1nc2ccccc2s1</smiles>

103

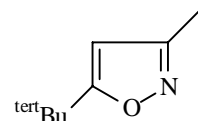

108

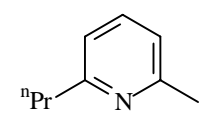

113

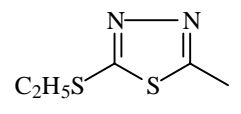

118

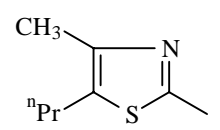

123<smiles>Cc1nc2c(Cl)cccc2s1</smiles>

104

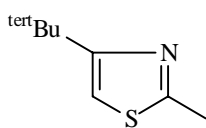

109<smiles>Cc1cnc(C)c(Br)c1</smiles>

114<smiles>Cc1cc(Br)cnc1C</smiles>

119

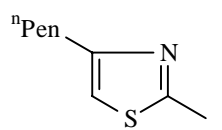

124<smiles>COc1cccc2sc(C)nc12</smiles>

105<smiles>Cc1ccc(Br)c(C)n1</smiles>

110

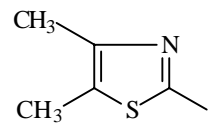

115

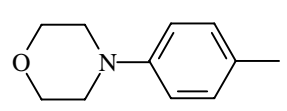

120

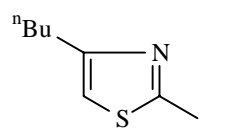

125

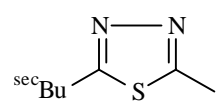

130

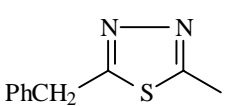

131<smiles>Cc1nc2ccc([N+](=O)[O-])cc2s1</smiles>

106<smiles>CCCc1cccc(C)n1</smiles>

111<smiles>Cc1ccc2c(c1)OCCO2</smiles>

116<smiles>CCc1sc(C)nc1C</smiles>

121

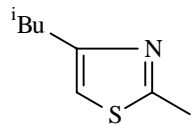

126

Figure 2. Structures of the 31 sulfamates synthesized in this work.

In Figure 2 the position of the sodium sulfamate function $-\mathrm{NHSO}_{3} \mathrm{Na}$ is indicated by the solid line.

In previous work we have had some success in deriving structure-taste relationships (SARs) for the first 33 compounds, ${ }^{10}$ then 56 compounds, ${ }^{11}$ and more recently 101 compounds. ${ }^{12}$ Each data set was examined using the Corey-Pauling-Koltun (CPK) parameters for the RNH portion of the heterosulfamate i.e. $\mathrm{RNHSO}_{3} \mathrm{Na}$ and a calculated first order molecular connectivity value $\left({ }^{1} \chi^{v}\right)$ for the molecule. The mathematical techniques of linear discriminant analysis (LDA) ${ }^{10,11,12}$ and quadratic discriminant analysis (QDA) ${ }^{10,11,12}$ and, more recently, Tree analysis ${ }^{12}$ have been employed in studying the data sets. The LDA and QDA analysis worsened somewhat as the size of the data set grew and thus Tree analysis was introduced to try to improve the classifications. In our last effort ${ }^{12}$ the LDA, QDA and Tree analyses correctly classified $65 \%$, $80 \%$ and $86 \%$ respectively of the 101 compounds of which 20 were sweet and 81 were non-sweet.

Table 1. Heterosulfamates synthesised for tastant studies 


\begin{tabular}{|c|c|c|}
\hline Groups (location) (years) & $\begin{array}{c}\text { No. of compounds } \\
\text { made }\end{array}$ & Reference \\
\hline Hurd and Kharasch (US) (1946) & 5 & 1 \\
\hline Blicke et al. (US) (1954) & 4 & 3 \\
\hline Thompson (US) (1957) & 1 & 4 \\
\hline Yamaguchi (Jap) (1963) & 1 & 5 \\
\hline $\begin{array}{l}\text { Unterhalt and Boschemeyer (Ger) (1972, } \\
\text { 1976) }\end{array}$ & 3 & 6,7 \\
\hline Wendt and Winkley (US) (1974) & 6 & 8 \\
\hline Evangelesti et al. (Italy) (1980) & 1 & 9 \\
\hline $\begin{array}{l}\text { Spillane et al. (Ireland) (1983, 1989, } 2000 \\
\text { and this paper) }\end{array}$ & $50^{\mathrm{a}}+31^{\mathrm{b}}$ & $\begin{array}{l}10,11,12 \text {, this } \\
\text { paper }\end{array}$ \\
\hline De Nardo et al. (Italy) (1984) & 8 & 13 \\
\hline Pautet and Daudon (France) (1986) & 9 & 14 \\
\hline Unterhalt and Moellers (Ger) $(1990,1991)$ & 13 & 15,16 \\
\hline Total & 132 & \\
\hline
\end{tabular}

${ }^{\mathrm{a}}$ Reported in 1983, 1989, 2000.

${ }^{\mathrm{b}}$ Reported in this paper.

In this current work we have synthesized and added an additional 31 new sulfamates to the data base of heterocompounds and of these 15 were found to be sweet and 16 were non-sweet. Thus the new enlarged database of 132 compounds contains 35 sweet compounds and 97 nonsweet compounds. Using again the descriptors $\mathrm{x}, \mathrm{y}, \mathrm{z}$ and $\mathrm{V}_{\mathrm{cpk}}$ (measured with Corey-PaulingKoltun models) and calculated first order molecular connectivity, ${ }^{1} \chi^{\mathrm{v}}$ together now with HOMO and LUMO energies, $E_{\text {solv, }}$ the solvation energy and $V_{\text {SPARTAN }}$ (all calculated using the SPARTAN program) (see Table 2) the LDA, QDA and Tree analyses (Tree 1) were carried out on this larger data set and the results are reported herein. A second Tree analysis (Tree 2) employed the Cerius2 program and used the physicochemical descriptors called Jurs parameters and shadow indices (see below).

\section{Results and Discussion}

Seven of the 2-aminothiazoles, precursors of sulfamates no. 121-127, employed in this current study were synthesized by reaction of the appropriate ketone with thiourea as shown in Scheme $\mathbf{1}^{20,21}$ and four of the 2-aminothiadiazoles, precursors of sulfamates no. 128-132 were synthesized by reaction of the appropriate carboxylic acid and thiosemicarbazide as illustrated in Scheme $2 .^{22}$ Full details of the syntheses of the aminothiazoles and aminothiadiazoles are given in the Experimental. 
Table 2. Values of the descriptors used in the LDA, QDA, and Tree 1 analysis for compounds 102-132 ${ }^{\mathrm{a}}$

\begin{tabular}{|c|c|c|c|c|c|c|c|c|c|c|}
\hline $\begin{array}{l}\text { Com- } \\
\text { pound }\end{array}$ & $\mathbf{x} / \AA$ & $\mathbf{y} / \AA ̊ \AA$ & $\mathbf{z} / \mathbf{A}$ & $\begin{array}{c}\mathbf{V}_{\mathbf{C P K}} / \\
\AA^{3}\end{array}$ & ${ }^{1} \chi^{\mathrm{V}}$ & HOMO & LUMO & $E_{\text {solv }}$ & $\mathbf{V}_{\text {SPARTAN }}$ & Taste \\
\hline 102 & 9.76 & 3.78 & 7.64 & 282 & 4.57 & -4.834 & 1.607 & 45.077 & 251.08 & $S$ \\
\hline 103 & 9.76 & 3.57 & 6.94 & 242 & 4.16 & & & 54.151 & & $\mathrm{~N}$ \\
\hline 104 & 9.76 & 3.53 & 8.41 & 290 & 4.64 & & & & & $\mathrm{~N}$ \\
\hline 105 & 9.76 & 5.27 & 8.88 & 457 & 4.69 & -5.536 & 2.656 & -219.20 & 239.88 & S \\
\hline 106 & 11.0 & 4.74 & 6.97 & 365 & 4.60 & -6.032 & 1.435 & -179.18 & 237.64 & $\mathrm{~N}$ \\
\hline 107 & 11.3 & 4.05 & 7.38 & 339 & 4.73 & -5.041 & & -190.54 & & $\mathrm{~N}$ \\
\hline 108 & 9.48 & 6.01 & 6.73 & 383 & 3.60 & -6.306 & 440 & -224.88 & 211.14 & $\mathrm{~N}$ \\
\hline 109 & 9.57 & 5.97 & 8.03 & 458 & 4.46 & -5.235 & 335 & -217.17 & 217.83 & $\mathrm{~N}$ \\
\hline 110 & 9.46 & 4.04 & 7.57 & 290 & 3.75 & -4.658 & 898 & -111.85 & 219.83 & $\mathrm{~N}$ \\
\hline 111 & 8.41 & 4.89 & 8.12 & 334 & 3.41 & -5.383 & 3.522 & -217.48 & 206.10 & S \\
\hline 112 & 7.82 & 6.02 & 9.62 & 453 & 2.77 & -5.4 & 3.450 & -216.18 & & $\mathrm{~N}$ \\
\hline 113 & 7.72 & 5.26 & 8.66 & 352 & 3.91 & -5.309 & 3.362 & -216.38 & 224.93 & S \\
\hline 114 & 8.42 & 3.76 & 7.73 & 244 & 3.74 & -5.534 & 3.027 & -212.43 & 211.02 & $\mathrm{~N}$ \\
\hline 115 & 8.25 & 4.46 & 6.53 & 240 & 2.97 & -5.244 & 0.959 & -101.99 & 205.07 & S \\
\hline 116 & 9.85 & 4.90 & 7.32 & 353 & 3.88 & -5.094 & 3.4393 & -287 & 219.66 & $\mathrm{~N}$ \\
\hline 117 & 8.54 & 4.97 & 6.20 & 263 & 3.29 & -5.7 & & & & $\mathrm{~S}$ \\
\hline 118 & 10.8 & 3.84 & 5.27 & 220 & 4.41 & -5.636 & & -192.96 & & S \\
\hline 119 & 9.35 & 4.46 & 7.20 & 300 & 3.74 & -5.590 & 3.056 & -212.81 & 211.40 & $\mathrm{~N}$ \\
\hline 120 & 11.2 & 6.34 & 7.64 & 543 & 4.91 & -5.075 & 3.512 & -250.57 & 264.39 & S \\
\hline 121 & 7.71 & 6.45 & 9.17 & 596 & 4.92 & -5.130 & 3.269 & -218.68 & 217.04 & $\mathrm{~N}$ \\
\hline 122 & 9.12 & 6.46 & 3.69 & 218 & 4.15 & & & & & S \\
\hline 123 & 8.32 & 6.54 & 5.06 & 276 & 4.81 & -5.181 & 3.245 & & 237.83 & $\mathrm{~N}$ \\
\hline 124 & 10.9 & 5.00 & 5.44 & 295 & 5.21 & -5.241 & 3.328 & -230.39 & 258.90 & S \\
\hline 125 & 10.3 & 5.17 & 5.48 & 292 & 5.13 & -5.237 & 3.334 & -223.80 & 238.36 & $\mathrm{~S}$ \\
\hline 126 & 8.65 & 9.20 & 5.76 & 454 & 4.57 & -5.233 & 3.317 & -221.33 & 238.08 & $\mathrm{~S}$ \\
\hline 127 & 7.20 & 7.92 & 4.64 & 265 & 4.10 & -5.224 & 3.352 & -214.92 & 217.47 & $\mathrm{~N}$ \\
\hline 128 & 6.80 & 5.44 & 4.60 & 170 & 2.75 & -6.249 & 2.132 & -330.250 & 193.71 & S \\
\hline 129 & 7.36 & 6.00 & 4.88 & 215 & 4.18 & -5.704 & 2.866 & -197.750 & 213.63 & S \\
\hline 130 & 8.64 & 5.44 & 6.24 & 293 & 4.99 & -5.717 & 2.856 & -203.177 & 233.94 & $\mathrm{~N}$ \\
\hline 131 & 10.1 & 6.80 & 7.52 & 515 & 4.92 & -5.792 & 2.342 & -161.470 & 261.60 & $\mathrm{~N}$ \\
\hline 132 & 8.80 & 5.96 & 3.76 & 197 & 3.86 & -5.719 & 2.837 & -200.902 & 214.62 & S \\
\hline
\end{tabular}

${ }^{a}$ The values for compounds 1-101 can be found in the Ph.D. Thesis of B. G. Feeney, NUI, Galway, 2003. 


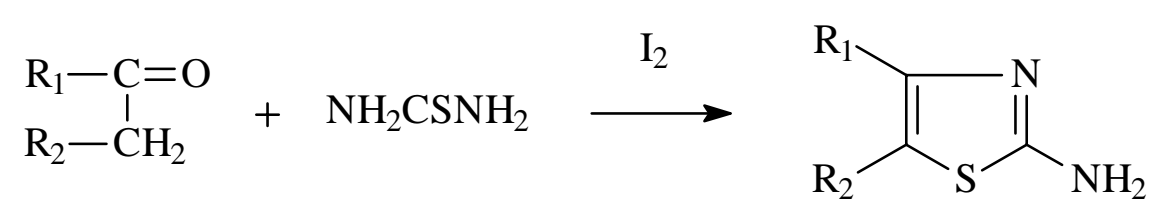

\section{Scheme 1}

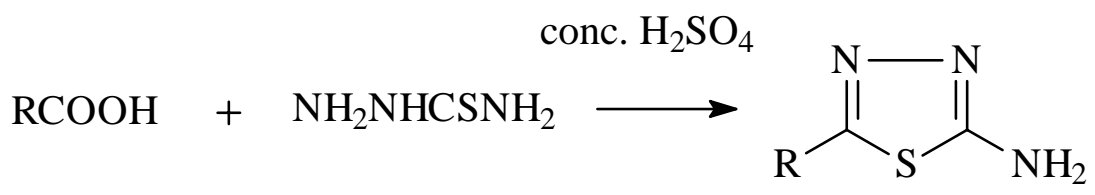

\section{Scheme 2}

The full taste portfolios and the taste conclusions i.e. sweet (S)/non-sweet $(\mathrm{N})$ for the thirty one new compounds, 102 - 132 are given in Table 3. Taste data conclusions (S/N) for compounds 1 - 33 are in ref. 10, for compounds 34 - 56 in ref. 11 and for compounds 57 - 101 in ref. 12. Examination of the Table shows that in a few cases there is no clear-cut predominant taste and a decision has to be made as to which category to assign the compound. Thus, in these cases the $\mathrm{S}$ and $\mathrm{N}$ categories become, as it were, to take a mythological example, Procrustean beds $^{18}$ into which everything has to be fitted. This arises because in the mathematical analysis employed one has to discriminate between two things be they black and white or sweet (S) and non-sweet $(\mathrm{N})$. Essentially there can be no grey areas since they cannot be accommodated and if compounds cannot be classified as $\mathrm{S}$ or $\mathrm{N}$ they would have to be omitted. After synthesizing and carrying out taste assessments for the compounds we prefer to strive to include them.

In reaching taste conclusions in Table 3 all those compounds where $\geq 50 \%$ of the tasters found a sweet taste were assigned to the sweet category i.e. $S$ and conversely if $\geq 50 \%$ of the tasters found that a non-sweet taste predominated they were assigned to the non-sweet category i.e. N. Compounds 119, 121 and 130 did not display any one single taste $\geq 50 \%$ but in the case of 119 no sweetness was detected so this compound obviously goes into the $\mathrm{N}$ category and compounds 121 and 130 display some sweetness but it is outweighed by a combination of nonsweet tastes so both of these compounds were assigned to the $\mathrm{N}$ category. Compounds such as 102 and 128 both have sweetness $\geq 50 \%$ accompanied by greater amounts of bitterness and bitterness/saltiness respectively. For the purposes of the analysis both of these were placed in the $S$ category since they do satisfy the criterion given above i.e. $\geq 50 \%$ sweetness present. Generally speaking we are satisfied with the classifications that we have made with all 132 compounds but of course it must be borne in mind that approximately 50 of the compounds have been reported in other laboratories and there has been controversy regarding some, for example, nos. 21-25 which are now taken to be non-sweet in this and in our last paper on this work. ${ }^{12}$ In fact with such a large group of compounds moving a few compounds from the $\mathrm{S}$ to $\mathrm{N}$ categories 
or vice versa makes little difference to the analysis and the percentages presented below in Table 4 are only very slightly affected.

Table 3. Taste data and taste conclusions $(\mathrm{S} / \mathrm{N})$ for heterosulfamates 102-132

\begin{tabular}{|c|c|c|c|c|c|c|c|c|c|}
\hline No. & pH & Sweet & Sour & Bitter & Salty & Tasteless & Aftertaste & $\begin{array}{c}\text { Predominant } \\
\text { taste ( } \geq 50 \% \\
\text { assessors) }\end{array}$ & $\mathbf{S} / \mathbf{N}$ \\
\hline 102 & 10.4 & 78 & 0 & 22 & 0 & 0 & Bitter 78 & Sweet & $\mathrm{S}$ \\
\hline 103 & 10.0 & 0 & 100 & 0 & 0 & 0 & 0 & Sour & $\mathrm{N}$ \\
\hline 104 & 9.90 & 67 & 0 & 100 & 0 & 0 & 0 & Bitter & $\mathrm{N}$ \\
\hline 105 & 10.4 & 100 & 0 & 0 & 0 & 0 & Bitter 44 & Sweet & $\mathrm{S}$ \\
\hline 106 & 10.7 & 0 & 0 & 100 & 0 & 0 & 0 & Bitter & $\mathrm{N}$ \\
\hline 107 & 8.80 & 0 & 55 & 55 & 0 & 0 & 0 & Sour/Bitter & $\mathrm{N}$ \\
\hline 108 & 11.5 & 0 & 100 & 33 & 0 & 0 & 0 & Sour & $\mathrm{N}$ \\
\hline 109 & 11.4 & 0 & 0 & 100 & 0 & 0 & 0 & Bitter & $\mathrm{N}$ \\
\hline 110 & 11.8 & 0 & 0 & 100 & 0 & 0 & 0 & Bitter & $\mathrm{N}$ \\
\hline 111 & 11.8 & 100 & 0 & 0 & 0 & 0 & 0 & Sweet & $\mathrm{S}$ \\
\hline 112 & 9.65 & 0 & 0 & 100 & 0 & 0 & Sour 55 & Bitter & $\mathrm{N}$ \\
\hline 113 & 11.5 & 55 & 0 & 0 & 65 & 0 & 0 & Sweet/Salty & $\mathrm{S}$ \\
\hline 114 & 7.10 & 0 & 50 & 50 & 0 & 0 & 0 & Sour/Bitter & $\mathrm{N}$ \\
\hline 115 & 9.65 & 50 & 40 & 0 & 10 & 0 & 0 & Sweet & $\mathrm{S}$ \\
\hline 116 & 9.02 & 20 & 0 & 60 & 0 & 0 & 0 & Bitter & $\mathrm{N}$ \\
\hline 117 & 8.70 & 100 & 0 & 0 & 0 & 0 & 0 & Sweet & S \\
\hline 118 & 8.65 & 80 & 10 & 40 & 0 & 0 & Bitter 50 & Sweet & $\mathrm{S}$ \\
\hline 119 & 7.27 & 0 & 30 & 20 & 20 & 30 & 0 & - & $\mathrm{N}$ \\
\hline 120 & 7.45 & 60 & 10 & 0 & 0 & 0 & 0 & Sweet & $\mathrm{S}$ \\
\hline 121 & 11.0 & 28 & 42 & 0 & 14 & 14 & 0 & - & $\mathrm{N}$ \\
\hline 122 & 11.5 & 71 & 0 & 28 & 28 & 0 & 0 & Sweet & S \\
\hline 123 & 11.5 & 28 & 57 & 14 & 0 & 14 & Sour 28 & Sour & $\mathrm{N}$ \\
\hline 124 & 11.5 & 57 & 14 & 42 & 14 & 0 & 0 & Sweet & S \\
\hline 125 & 11.2 & 85 & 14 & 0 & 14 & 0 & Sour 42 & Sweet & $\mathrm{S}$ \\
\hline 126 & 11.5 & 71 & 14 & 14 & 0 & 14 & Sour 14 & Sweet & $\mathrm{S}$ \\
\hline 127 & 10.9 & 0 & 50 & 50 & 0 & 0 & 0 & Sour/Bitter & $\mathrm{N}$ \\
\hline 128 & 8.70 & 50 & 0 & 12 & 50 & 0 & 0 & Sweet/Salty & $\mathrm{S}$ \\
\hline 129 & 10.2 & 75 & 0 & 0 & 12 & 12 & Sour 25 & Sweet & $\mathrm{S}$ \\
\hline 130 & 10.3 & 37 & 12 & 25 & 37 & 12 & 0 & - & $\mathrm{N}$ \\
\hline 131 & 10.0 & 25 & 62 & 0 & 0 & 12 & 0 & Sour & $\mathrm{N}$ \\
\hline 132 & 10.2 & 50 & 12 & 12 & 12 & 12 & Sour 12 & Sweet & $\mathrm{S}$ \\
\hline
\end{tabular}


The parameters for the analysis are brought together in Table 2 and the results for each analysis are given in Table 4. First various parameter subsets were tried in the analysis and the best subset was found to be that using LUMO, ${ }^{1} \chi \mathrm{v}, \mathrm{V}_{\mathrm{CPK}}$ and $\mathrm{y}$. The LDA analysis correctly classifies $70 \%$ of the compounds and the percentage of sweet compounds correctly classified is 24/35 \% i.e. $69 \%$ and of non-sweet 68/97 \% i.e. $70 \%$. QDA correctly classifies $68 \%$ and the percentages of sweet and non-sweet correctly classified by this method are 24/35 \% i.e. $69 \%$ and 66/97 \% i.e. $68 \%$ respectively. The Tree analysis (Tree 1) performs well and correctly classifies $81 \%$ of the compounds with 30/35 \% i.e. $86 \%$ of sweet and 75/97 \% i.e. $77 \%$ of non-sweet correctly classified. In this analysis various combinations of parameters were tried and the subset giving the best overall \% classification was that utilizing the parameters LUMO, $\mathrm{z}, \mathrm{y}$ and $\mathrm{V}_{\mathrm{CPK}}$. The Tree 1 analysis is shown in Figure 3 below.

Table 4. Summary of results of LDA, QDA, Tree 1 and Tree 2 analysis for 132 heterosulfamates

\begin{tabular}{cccc}
\hline Method & \multicolumn{2}{c}{ Correctly classified } & Overall \% classified \\
& \%Sweet & \%Non-sweet & \\
\hline LDA & 69 & 70 & 70 \\
QDA & 69 & 68 & 68 \\
Tree 1 & 86 & 77 & 81 \\
Tree 2 & 61 & 51 & 54 \\
\hline
\end{tabular}

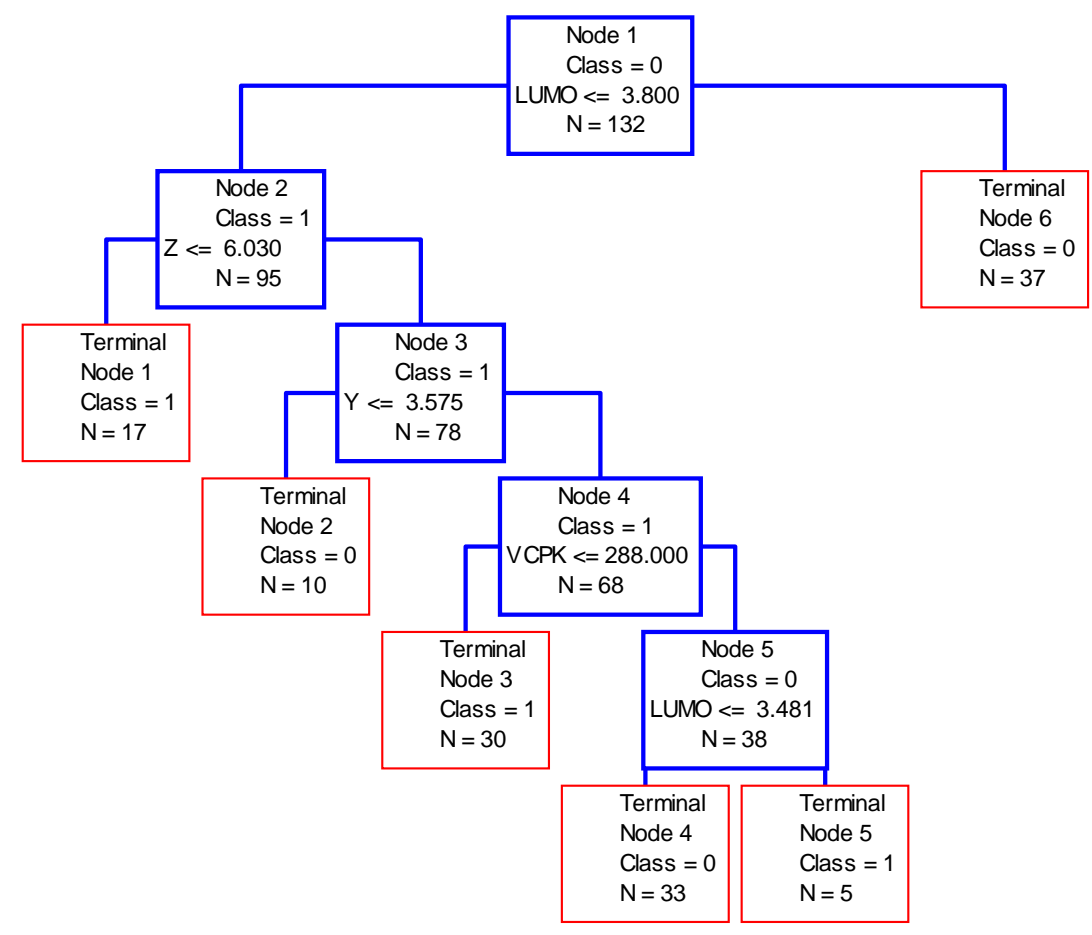

Figure 3. Tree 1 , Sweet $=$ Class 1 ; Non-sweet $=$ Class 0 . 
An alternative Tree analysis (Tree 2) using the Cerius2 program and different parameters available in the program, namely Jurs descriptors (combines shape and electronic information on the molecule) and shadow indices (a set of geometric descriptors to characterize the shape of the molecule) has also been carried out. This Tree analysis was not at all as successful and only classified 71 of the compounds correctly i.e. $54 \%$. It correctly classified 24/35 \% i.e $68 \%$ of the sweet compounds and $47 / 92 \%$ i.e. $51 \%$ of the non-sweet compounds. Details of the physicochemical parameters used are available. $^{19}$

In summary considering that a further 31 compounds have been added to the data base giving a total set of 132 compounds in all representing many diverse (mainly heterocyclic) structures the results are reasonable and the SARs found do classify the sweet and non-sweet compounds satisfactorily. Future work is likely to concentrate more on certain categories bearing close structural resemblances.

\section{Experimental Section}

\section{Precursor Amines}

Nineteen of the starting amines were available commercially from Aldrich and Lancaster. These were used without further purification.

\section{2-Aminothiazoles}

The precursor amines for the seven thiazolylsulfamates nos. (121) - (127) were synthesized (Scheme 1) based on the methods of Dodson and $\mathrm{King}^{20}$ and King and Hlavacek ${ }^{21}$ with some modifications. The ketone $(0.1 \mathrm{~mol})$ and thiourea $(0.2 \mathrm{~mol})$ were placed in a round bottomed flask and iodine $(0.1 \mathrm{~mol})$ was added all at once. After this addition the reaction mixture was stirred overnight under reflux at $100^{\circ} \mathrm{C}$. The reaction mixture was then diluted with hot water at which point a small amount of free sulfur precipitated. The aqueous solution was cooled and filtered to remove the sulfur and was washed with diethyl ether (3-4 times) to extract the unreacted ketone and iodine. Concentrated ammonium hydroxide solution was then added and an oil separated. This was then separated using a separating funnel and the aqueous solution was extracted two more times and added to the oil. The diethyl ether solution containing the amine was dried over magnesium sulfate. The magnesium sulfate was filtered and the ether solution was reduced on a rotary evaporator leaving the crude 2-aminothiazole which was purified using flash chromatography $\left(40^{\circ}-60^{\circ}\right.$ petroleum spirit-diethyl ether 50:50). All seven 2-aminothiazoles are previously known compounds.

4-Methyl-5-ethyl-2-aminothiazole (precursor of 121). As above, giving dark brown oil, 46\% yield. ${ }^{1} \mathrm{H}$ NMR (DMSO-d $\left.)_{6}\right): \delta 1.07$ (t, 3H, $\mathrm{CH}_{3}$ ), 1.94 (s, 3H, $\mathrm{CH}_{3} \mathrm{CH}_{2}$ ), $2.45\left(\mathrm{q}, \mathrm{CH}_{3} \mathrm{CH}_{2}\right.$ ), 6.51 
(s, 2H, NH $\mathrm{NH}_{2}$. ${ }^{13} \mathrm{C}$ NMR: $\delta 14.36$ (C8), 16.44 (C7), 18.99 (C5), 119.53 (C6), 141.06 (C4), 164.41 (C2).

4-N-propyl-2-aminothiazole (precursor of 122). As above, giving pale yellow oil, 36\% yield. ${ }^{1} \mathrm{H}$ NMR (DMSO-d ${ }_{6}$ ): $\delta 0.90$ (t, 3H, $\mathrm{CH}_{3}$ ), 1.53 (m, $\mathrm{CH}_{2}$ ), 2.34 (t, 2H, $\mathrm{CH}_{2}$ ), 6.05 (s, 1H, C-H), 6.79 (s, 2H, $\mathrm{NH}_{2}$ ). ${ }^{13} \mathrm{C}$ NMR: $\delta 13.64$ (C7), 21.45 (C6), 33.26 (C5), 99.88 (C8), 152.14 (C4), 167.94 (C2).

4-Methyl-5-n-propyl-2-aminothiazole (precursor of 123). As above, giving dark brown oil, $42 \%$ yield. ${ }^{1} \mathrm{H}$ NMR (DMSO- $d_{6}$ ): $\delta 0.91\left(\mathrm{t}, 3 \mathrm{H}, \mathrm{CH}_{3}\right.$ ), $1.46\left(\mathrm{~m}, 2 \mathrm{H}, \mathrm{CH}_{3} \mathrm{CH}_{2} \mathrm{CH}_{2}\right.$ ), 2.03 (s, 3H, $\mathrm{CH}_{3}$ ), 2.50 (t, $\left.2 \mathrm{H}, \mathrm{CH}_{3} \mathrm{CH}_{2} \mathrm{CH}_{2}\right), 6.60$ (s, $2 \mathrm{H}, \mathrm{NH}_{2}$ ).

${ }^{13}$ C NMR: $\delta 13.30$ (C9), 14.45 (C8), 24.55 (C7), 27.48 (C5), 117.62 (C6), 141.78 (C4), 164.63 (C2).

4-n-Pentyl-2-aminothiazole (precursor of 124). As above, giving pale yellow oil, 42\% yield. ${ }^{1} \mathrm{H}$ NMR (DMSO-d $)_{6}$ ) $\delta 0.90$ (t, 3H, $\mathrm{CH}_{3}$ ), 1.23-1.27 (m, 4H, $2 \times \mathrm{CH}_{2}$ ), $1.54\left(\mathrm{~m}, 2 \mathrm{H}, \mathrm{CH}_{2}\right), 2.37$ (t, 2H, $\mathrm{CH}_{2}$ ), 6.06 (s, 1H, C-H), 6.81 (s, 2H, NH 2$) .{ }^{13} \mathrm{C}$ NMR: $\delta 14.43$ (C9), 22.46 (C8), 23.58 (C7), 28.48 (C6), 31.67 (C5), 100.28 (C10), 149.37 (C4), 167.28 (C2).

4-n-Butyl-2-aminothiazole (precursor of 125). As above, giving viscous pale yellow oil that solidified on standing, 45\% yield. ${ }^{1} \mathrm{H}$ NMR (DMSO- $d_{6}$ ): $\delta 0.94\left(\mathrm{t}, 3 \mathrm{H}, \mathrm{CH}_{3}\right), 1.25(\mathrm{~m}, 2 \mathrm{H}$, $\mathrm{CH}_{3} \mathrm{CH}_{2^{-}}$), 1.47 (m, 2H, $\mathrm{CH}_{2}$ ), 2.36 (t, 2H, $\left.\mathrm{CH}_{2}\right), 6.07$ (s, $\left.1 \mathrm{H}, \mathrm{C}-\mathrm{H}\right), 6.80$ (s, $\left.2 \mathrm{H}, \mathrm{NH}_{2}\right) .{ }^{13} \mathrm{C}$ NMR: $\delta 13.81$ (C8), 21.84 (C7), 30.50 (C6), 30.92 (C5), 99.79 (C9), 152.44 (C4), 168.02 (C2).

4-Isobutyl-2-aminothiazole (precursor of 126). As above, giving dark brown oil that solidified on standing, 56\% yield. ${ }^{1} \mathrm{H}$ NMR (DMSO- $d_{6}$ ): $\delta 0.90$ (d, 6H, $2 \times \mathrm{CH}_{3}$ ), $1.90(\mathrm{~m}, 1 \mathrm{H}, \mathrm{CH}), 2.23$ (d, 2H, $\mathrm{CH}_{2}$ ), 6.06 (s, 1H, C-H), 6.75 (s, 2H, $\mathrm{NH}_{2}$ ). ${ }^{13} \mathrm{C}$ NMR: 822.30 (C7, C8), 27.36 (C6), 32.20 (C5), 98.56 (C9), 153.65 (C4), 168.58 (C2).

4-Isopropyl-2-aminothiazole (precursor of 127). As above, giving yellow oil, 65\% yield. ${ }^{1} \mathrm{H}$ NMR (DMSO-d $\left.d_{6}\right): \delta 1.10$ (d, 6H, 2 x CH 3 ), 2.82 (m, 1H, CH), 5.87 (s, broad, 2H, $\mathrm{NH}_{2}$ ), 6.01 (s, 1H, C-H). ${ }^{13}$ C NMR: $\delta 21.78$ (C6), 22.03 (C7), 30.82 (C5), 99.69 (C9), 159.30 (C4), 168.17 (C2).

\section{2-Amino-1,3,4-thiadiazoles}

The precursor amines required for the synthesis of the four 1,3,4- thiadiazolesulfamates nos. (129) - (132) were made (Scheme 2) based on the method of Chubb and Nissenbaum ${ }^{22}$. The carboxylic acid $(0.15 \mathrm{~mol})$ and thiosemicarbazide $(0.125 \mathrm{~mol})$ was stirred in $16 \mathrm{ml}$ of concentrated sulfuric acid in a round bottomed flask at $80^{\circ}-90^{\circ} \mathrm{C}$ for 7 hours under reflux. After the reaction was complete the reaction mixture was allowed to cool and poured into ice water. The mixture was basified using concentrated ammonium hydroxide solution. On addition of the base the thiadiazole product precipitated. This was filtered and the crude product obtained. It was recrystallized from aqueous ethanol (10-15\%). The pure product was dried over phosphorus pentoxide under vacuum for 24 hours. The four amines synthesized are previously known compounds. 
5-Isopropyl-2-amino-1,3,4- thiadiazole (precursor of 129). As above, giving an off white powdered product, 70\% yield. ${ }^{1} \mathrm{H}$ NMR (DMSO- $\left.d_{6}\right): \delta 1.23\left(\mathrm{~d}, 6 \mathrm{H}, 2 \times \mathrm{CH}_{3}\right), 3.15(\mathrm{~m}, 1 \mathrm{H}, \mathrm{CH})$, 7.05 (s, 2H, $\mathrm{NH}_{2}$ ). ${ }^{13} \mathrm{C}$ NMR: $\delta 19.25$ (C8), 22.64 (C7), 30.03 (C6), 164.63 (C5), 167.90 (C2).

5-sec-Butyl-2-amino-1,3,4- thiadiazole (precursor of 130). As above, giving an off white powdered product, 64\% yield. ${ }^{1} \mathrm{H}$ NMR (DMSO-d $\left.d_{6}\right): \delta 0.90\left(\mathrm{t}, 3 \mathrm{H}, \mathrm{CH}_{3} \mathrm{CH}_{2}\right), 1.28\left(\mathrm{~d}, 3 \mathrm{H}, \mathrm{CH}_{3}\right)$, 1.65 (m, 2H, $\mathrm{CH}_{2}$ ), 2.99 (m, 1H, CH), 5.70 (s, broad, 2H, $\mathrm{NH}_{2}$ ). ${ }^{13} \mathrm{C}$ NMR: 11.57 (C9), 20.70 (C8), 30.51 (C7), 37.73 (C6), 163.27 (C5), 167.23 (C2).

5-Benzyl-2-amino-1,3,4- thiadiazole (precursor of 131). As above, giving a light yellow powdered product, 36\% yield. ${ }^{1} \mathrm{H}$ NMR (DMSO- $d_{6}$ ): $\delta 4.12$ (s, $2 \mathrm{H}, \mathrm{CH}_{2}$ ), 7.01 (s, $2 \mathrm{H}, \mathrm{NH}_{2}$ ), 7.26 (m, all aromatic H). ${ }^{13} \mathrm{C}$ NMR: 35.47 (C6), 126.84, 128.54, 128.66, 139.29 (all aromatic C), 164.23 (C5), 168.95 (C2).

5-n-Propyl-2-amino-1,3,4- thiadiazole (precursor of 132). As above, giving an off white powdered product, 75\% yield. ${ }^{1} \mathrm{H}$ NMR (DMSO- $\left.d_{6}\right): \delta 0.91\left(\mathrm{t}, 3 \mathrm{H}, \mathrm{CH}_{3}\right), 1.63\left(\mathrm{~m}, 2 \mathrm{H}, \mathrm{CH}_{2}\right)$, 2.75 (t, 2H, $\mathrm{CH}_{2}$ ), 7.00 (s, 2H, $\mathrm{NH}_{2}$ ). ${ }^{13} \mathrm{C}$ NMR: $\delta 18.49$ (C8), 27.62 (C7), 36.49 (C6), 163.36 (C5), 173.30 (C2).

\section{Preparation of Sulfamates}

The methods used for the synthesis of the heterosulfamates were based on those of Audrieth and Sveda $^{2}$ and Boyland, Manson and Orr ${ }^{23}$ and are represented in Scheme 3.

$$
\begin{aligned}
& \mathrm{C}_{5} \mathrm{H}_{5} \mathrm{~N}(\mathrm{ex})+\mathrm{ClSO}_{3} \mathrm{H} \stackrel{0^{0} \mathrm{C}}{\longrightarrow} \mathrm{C}_{5} \mathrm{H}_{5} \mathrm{~N} \mathrm{SO}_{3}+\mathrm{C}_{5} \mathrm{H}_{5} \mathrm{~N} . \mathrm{HCl} \\
& \mathrm{C}_{5} \mathrm{H}_{5} \mathrm{~N} \mathrm{SO}_{3}+\mathrm{RNH}_{2} \stackrel{\mathrm{RT}}{\longrightarrow} \mathrm{RNHSO}_{3}{ }^{-} \mathrm{C}_{5} \mathrm{H}_{5} \mathrm{NH}^{+} \stackrel{\mathrm{NaOH}}{\longrightarrow} \mathrm{RNHSO}_{3}{ }^{-} \mathrm{Na}^{+}
\end{aligned}
$$

\section{Scheme 3}

Chlorosulfonic acid was added dropwise over 20 mins. to a 10 molar excess of dried pyridine stirring in a three-necked round bottom flask equipped with a calcium chloride drying tube. The reaction flask was immersed in an ice-salt-acetone bath to maintain the temperature at $<0^{0} \mathrm{C}$. The reaction mixture was allowed to stir for an hour once all the chlorosulfonic acid was added. The liquid or solid amine, dissolved in the minimum amount of dry pyridine, was added to the solid sulfur trioxide adduct dissolved in pyridine. The cooling bath was taken away and the reaction mixture was allowed to come to room temperature and stirred overnight. An appropriate amount of $2 \mathrm{M}$ sodium hydroxide was then added to form the sodium salt of the sulfamate. Enough was added to bring the $\mathrm{pH}$ to $\sim 10$, the N-S sulfamate bond being stable under these alkaline conditions. Unreacted amine was separated at this stage by several extractions with diethyl ether. 
The resultant aqueous solution was concentrated to a low volume on the rotary evaporator to yield the crude sulfamate. The sodium sulfamate product was purified by repeated recrystallization (generally 3 or 4 ) from aqueous ethanol (the exact percentage of aqueous ethanol required varies according to the sulfamate being synthesized, generally it is $~ 95 \%)$. The pure sodium sulfamate product was filtered and dried over phosphorus pentoxide in a vacuum dessicator for at least 48 hours before elemental analysis was carried out. The $\mathrm{C}, \mathrm{H}$ and $\mathrm{N}$ analysis figures were within $\pm 0.5 \%$ for all 31 sulfamates except the following: anal. calcd. for (108) H, 5.39. Found 3.83; calcd. for (109) H, 5.44. Found, 4.32 and N, 8.97. Found, 6.99; calcd. for (111) C, 31.55. Found: 30.61 and calcd. for (125) C, 26.92. Found 27.45. The sodium sulfamates were characterized further by IR and they all showed the typical sulfamate frequencies: $v \mathrm{SO}_{3}$ (asymm.) $1240-1210 \mathrm{~cm}^{-1} ; v \mathrm{SO}_{3}$ (symm.) $1203-1170 \mathrm{~cm}^{-1} ; v \mathrm{SO}_{3}$ (asymm.) 1070-1040 $\mathrm{cm}^{-1}$; vNS 730-660 $\mathrm{cm}^{-1}$; vNH 3400-3190 $\mathrm{cm}^{-1}$.

Finally all the prepared sulfamates gave a positive and clean (i.e. no sulfate ion present) sulfamate test. ${ }^{24}$

\section{Tasting procedures, CPK measurements and molecular connectivity and theoretical calculations}

The procedures and methodology for the tasting procedure, CPK measurements and molecular connectivity calculations were similar to those previously described. ${ }^{12}$ For the tasting procedure $8 \mathrm{ml}$ aliquots of $0.01 \mathrm{M}$ solutions were given to the panelists. For compounds 102-113 nine panelists were used, for 114-120 ten panelists were used, for 121-126 seven panelists were used and for 127-132 eight panelists were used. Some sulfamates had occluded water of recrystallizations and allowance was made for this when making up the solutions for tasting.

The structures of all 132 heterosulfamates were built using PC SPARTAN $P R O^{25}$ software. The equilibrium geometry was obtained using the semi-empirical AM1 module within the software and the HOMO, LUMO, $\mathrm{E}_{\text {solv }}$ and $\mathrm{V}_{\text {SPARTAN }}$ properties were calculated for each heterosulfamate. These properties, along with the CPK parameters were used for the LD, QD and Tree 1 analyses. LDA and QDA were carried out using the statistical software SYSTAT $10{ }^{26}$ The Tree 1 analysis was performed using the software CART $4.0^{27}$. For the Tree 2 analysis all 132 heterosulfamates were built using Cerius $2^{28}$ software and the various physicochemical descriptors ${ }^{19}$ were generated within the software. The Tree 2 analysis was carried out using the SYSTAT 10 program. ${ }^{26}$

\section{Acknowledgements}

L.M.K. acknowledges a grant from Enterprise Ireland and L.M.K. and B.G.F. thank Galway Co. Council for financial assistance. Some of this work was also supported by the EU-AIR and EUFAIR schemes. 


\section{References}

1. Hurd, C. D.; Kharasch, M. J. Am. Chem. Soc. 1946, 68, 653.

2. Audrieth, L. F.; Sveda, M. J. Org. Chem. Soc. 1944, 9, 89.

3. Blicke, F.F.; Millson, H. E.; Doorenbos, N.J. J. Am. Chem. Soc. 1954, 76, 2498.

4. Thompson, W. W. US Patent 2805 124, 1957; Chem. Abstr. 1958, 52, 9221.

5. Yamaguchi, H. Japan Patent 13 056, 1963; Chem. Abstr. 1964, 60, 2771.

6. Unterhalt, B.; Boschemeyer, L. Naturwissenschaften 1972, 59, 271.

7. Unterhalt, B.; Boschemeyer, L. Z. Lebensm. Unters. Forsch. 1976, 161, 275.

8. Wendt, G. R.; Winkley, M. W. US Patent 3787 442. 1974; Chem. Abstr. 1974, 80, 82669.

9. Evangelisti, F; Bargagna, A.; Schenone, P. Riv. Soc. Ital. Sci. Aliment. 1980, 9, 435; Chem. Abstr. 1981, 95, 115755.

10. Spillane, W. J.; McGlinchey, G.; O’Muircheartaigh, I.; Benson, G. A. J. Pharm. Sci. 1983, 72, 852.

11. Spillane, W. J.; Sheahan, M.B. J. Chem. Soc., Perkin Trans. 2 1989, 741.

12. Spillane, W. J.; Ryder, C. A.; Curran, P .J.; Wall, S. N.; Kelly, L. M.; Feeney, B. G.; Newell, J. J. Chem. Soc., Perkin Trans. 2, 2000, 1369.

13. DeNardo, M.; Runti, C.; Ulian, F. Farmaco, Ed. Sci. 1984, 39, 125; Chem. Abst. 1984, 100, 137569.

14. Pautet, F.; Daudon, M. Pharm. Acta Helv. 1986, 61, 215.

15. Unterhalt, B.; Moellers, M. Arch. Pharm. (Weinheim). 1990, 323, 317.

16. Unterhalt, B.; Moellers, M. Sci. Pharm. 1991, 59, 173.

17. Roy, G. Critical Reviews in Food Science and Nutrition. 1992, 31, 59, CRC Press, Inc.

18. Graves, R. The Greek Myths. Volume 1, 2002. The Folio Society, London.

19. Channa K. Hattotuwagama, Ph.D. Thesis, University of Reading, Department of Chemistry, 2002.

20. Dodson, R.M.; King Carroll, L. J. Am. Chem. Soc. 1944, 67, 2242.

21. King Carroll, L.; Hlavacek, R.J. J. Am. Chem. Soc.1950, 72, 3722.

22. Chubb, F.L.; Nissenbaum, J. Can. J. Chem. 1959, 37, 1121.

23. Boyland, E.; Manson, D.; Orr, S.F.D. Biochem. J. 1957, 65, 417.

24. Benson, G.A.; Spillane, W.J. J. Med. Chem. 1976, 19, 869.

25. Wavefunction Inc., PC SPARTAN PRO program, 2000. California, USA.

26. SPSS Inc., SYSTAT 10 program, 2000. Illinois, USA.

27. Salford Systems, CART 4.0 program, 2000. California, USA.

28. Molecular Simulations/Biosym Inc., Cerius2 program, 1998. California, USA. 